\title{
Report on the FY18 Uniaxial Material Model Testing and Key Feature Test Articles Testing of Grade 91
}

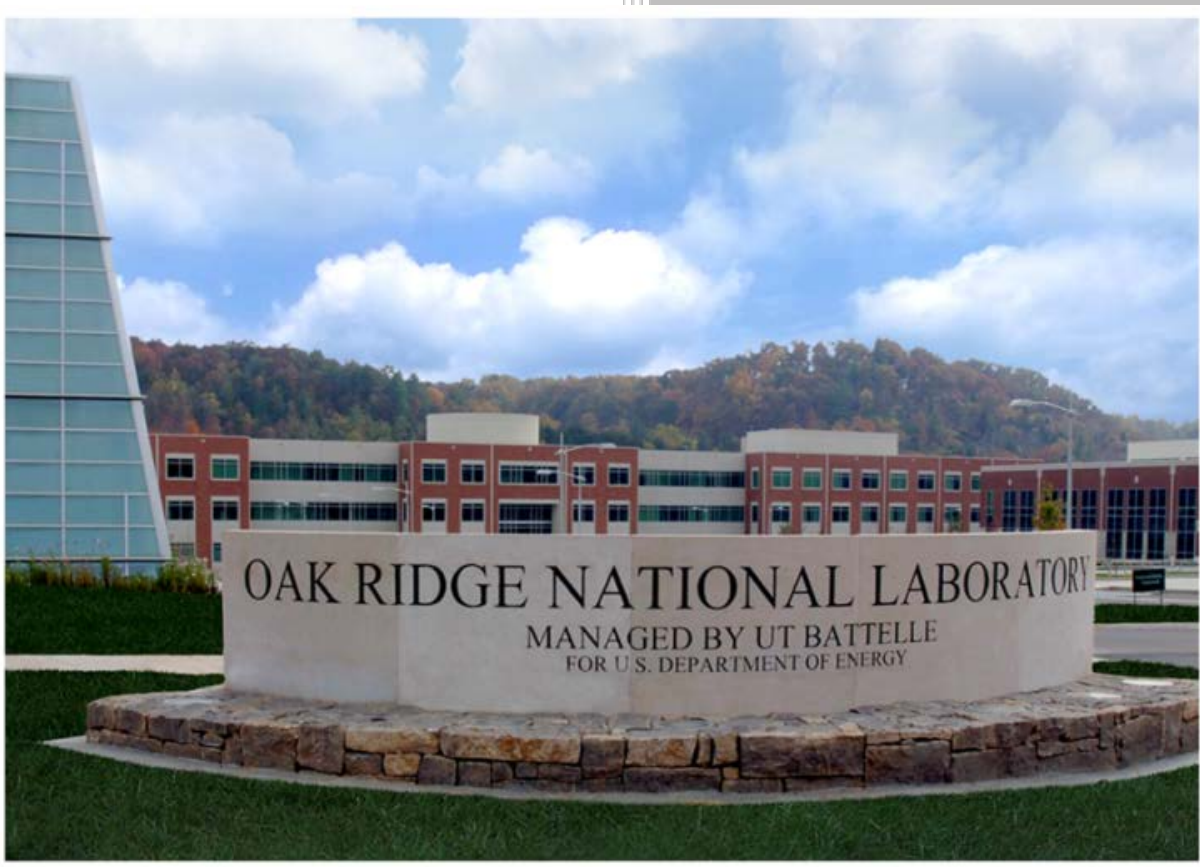

Approved for public release. Distribution is unlimited.

Yanli Wang Mark C. Messner

T.-L. Sham

July 6, 2018 


\title{
DOCUMENT AVAILABILITY
}

Reports produced after January 1, 1996, are generally available free via US Department of Energy (DOE) SciTech Connect.

\section{Website http://www.osti.gov/scitech/}

Reports produced before January 1, 1996, may be purchased by members of the public from the following source:

\author{
National Technical Information Service \\ 5285 Port Royal Road \\ Springfield, VA 22161 \\ Telephone 703-605-6000 (1-800-553-6847) \\ TDD 703-487-4639 \\ Fax 703-605-6900 \\ E-mail info@ntis.gov \\ Website http://www.ntis.gov/help/ordermethods.aspx
}

Reports are available to DOE employees, DOE contractors, Energy Technology Data Exchange representatives, and International Nuclear Information System representatives from the following source:

Office of Scientific and Technical Information

PO Box 62

Oak Ridge, TN 37831

Telephone 865-576-8401

Fax 865-576-5728

E-mail reports@osti.gov

Website http://www.osti.gov/contact.html

This report was prepared as an account of work sponsored by an agency of the United States Government. Neither the United States Government nor any agency thereof, nor any of their employees, makes any warranty, express or implied, or assumes any legal liability or responsibility for the accuracy, completeness, or usefulness of any information, apparatus, product, or process disclosed, or represents that its use would not infringe privately owned rights. Reference herein to any specific commercial product, process, or service by trade name, trademark, manufacturer, or otherwise, does not necessarily constitute or imply its endorsement, recommendation, or favoring by the United States Government or any agency thereof. The views and opinions of authors expressed herein do not necessarily state or reflect those of the United States Government or any agency thereof. 
ORNL/TM- 2018/885

Materials Science and Technology Division

\title{
REPORT ON THE FY18 UNIAXIAL MATERIAL MODEL TESTING AND KEY FEATURE TEST ARTICLES TESTING OF GRADE 91
}

\author{
Yanli Wang, Mark C. Messner* and T.-L. Sham* \\ *Argonne National Laboratory
}

July 6, 2018

Prepared by

OAK RIDGE NATIONAL LABORATORY

Oak Ridge, TN 37831-6283

managed by

UT-BATTELLE, LLC

for the

US DEPARTMENT OF ENERGY

under contract DE-AC05-00OR22725 



\section{CONTENTS}

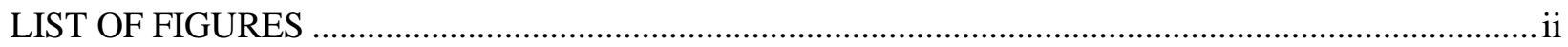

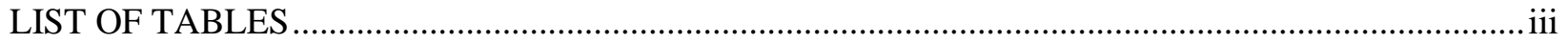

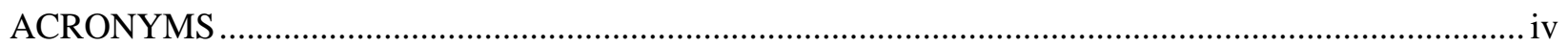

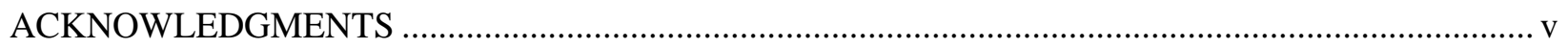

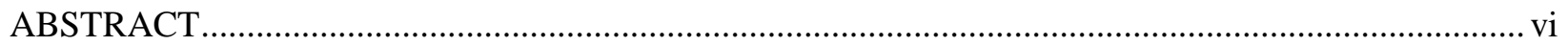

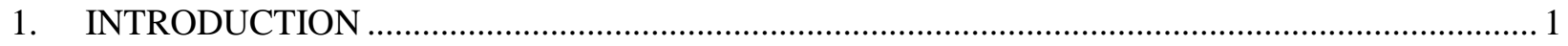

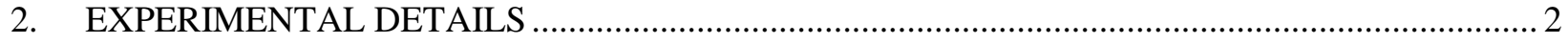

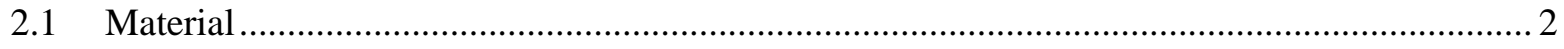

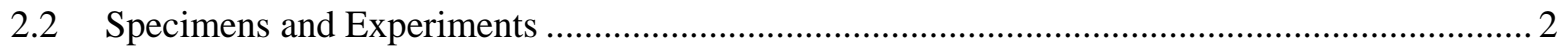

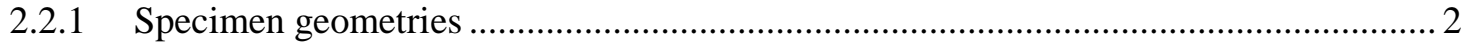

2.2.2 Key feature mechanical testing ............................................................................. 3

2.2.3 Thermomechanical fatigue to support the viscoplastic material model

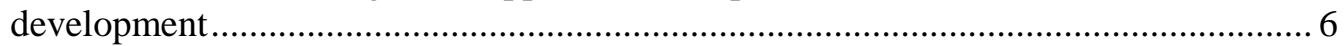

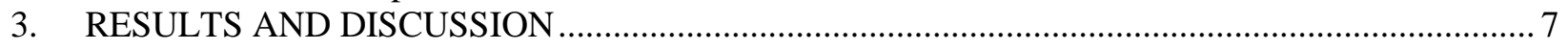

3.1 Results from Key Feature Mechanical Testing ..................................................................... 7

3.1.1 Effect of pre-cyclic softening on Type 1 SMT creep fatigue....................................... 7

3.1.2 Two-bar thermal ratchet test results on pre-softened Gr. 91........................................ 9

4. UNIAXIAL MECHANICAL TESTING IN SUPPORT OF VISCOPLASTIC MATERIAL

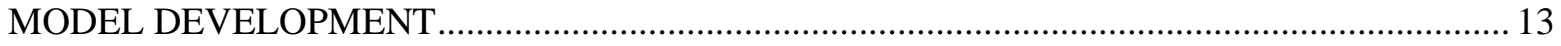

4.1 Summary of Previous Test Results on Material Model Development for Gr. 91 .................... 13

4.2 Thermomechanical Test Results on Gr. 91 at $500{ }^{\circ} \mathrm{C}$ to $600{ }^{\circ} \mathrm{C}$............................................ 13

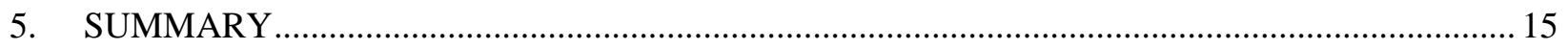

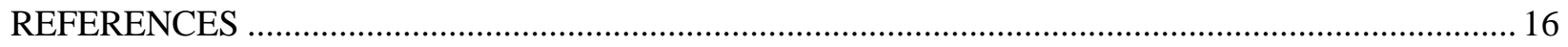




\section{LIST OF FIGURES}

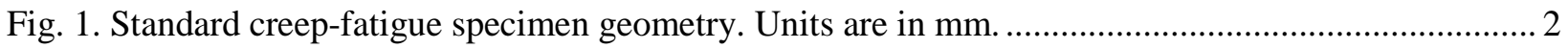

Fig. 2. Type 1 SMT solid bar specimen geometry. Units are in mm. .................................................... 3

Fig. 3. Applied loading profile for one cycle of pre-cyclic softening (a) and SMT creep-fatigue

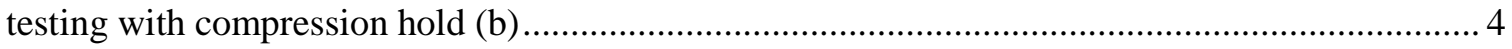

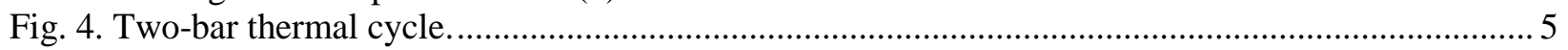

Fig. 5. Schematics of the anti-phase thermomechanical fatigue for two cycles ....................................... 6

Fig. 6. Comparison of the Type 1 SMT creep -fatigue test results at $650^{\circ} \mathrm{C}$ on Gr. 91 (heat 30176) with and without pre-softening cycles. The 170 pre-softening cycles were introduced to the specimen at $600{ }^{\circ} \mathrm{C}$ at $1 \%$ strain range under fully reversed pure fatigue loading......

Fig. 7. Representative hysteresis loops for the Type 1 SMT creep -fatigue test at $650^{\circ} \mathrm{C}$ on Gr. 91 (heat 30176) with pre-softening cycles (a) and without pre-softening (b). The 170 presoftening cycles were introduced to the specimen at $600{ }^{\circ} \mathrm{C}$ at $1 \%$ strain range under fully reversed pure fatigue loading.

Fig. 8. Representative normalized stress relaxation curves for the Type 1 SMT creep -fatigue test at $650^{\circ} \mathrm{C}$ on Gr. 91 (heat 30176) with pre-softening cycles. The 170 pre-softening cycles were introduced at $600{ }^{\circ} \mathrm{C}$ at $1 \%$ strain range under fully reversed pure fatigue loading............... 9

Fig. 9. One cycle of the thermal profile with 6 minutes delay for the two-bar test .................................. 10

Fig. 10. Comparison of the two-bar thermal ratcheting behavior of unsoftened Gr. 91 and presoftened Gr. 91 under combined total load of $-445 \mathrm{~N}$ (a), $3115 \mathrm{~N}$ (b), $4005 \mathrm{~N}$ (c) and $5118 \mathrm{~N}$ (d) and with 10 minutes time delay. Open circles are the minimum total strain and the filled circles are the maximum total strain.

Fig. 11. Comparison of the 350-hr accumulated strains for softened and un-softened Gr. 91 tested with 10-minutes delay under two-bar thermal ratchet condition

Fig. 12. Thermo-mechanical fatigue at temperature range of 500 to $600{ }^{\circ} \mathrm{C}$.......................................... 14 


\section{LIST OF TABLES}

Table 1. Chemical compositions of Gr. 91 plate with heat number 30176 (weight \%)............................. 2

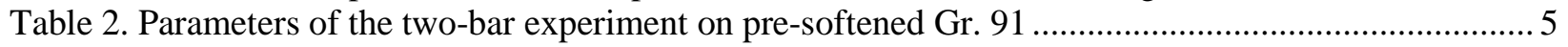

Table 3. Test parameters for thermomechanical experiment on Gr. 91 (heat 30176)................................. 6

Table 4. Summary of the SMT creep-fatigue results ....................................................................... 7

Table 5. Summary of the two-bar thermal ratcheting experiments for temperature range of 350 to

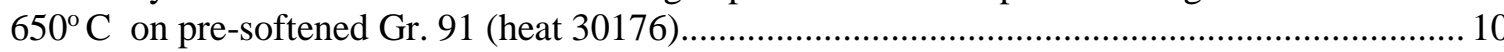




\section{ACRONYMS}

$\begin{array}{ll}\text { ART } & \text { Advanced Reactor Technologies } \\ \text { ANL } & \text { Argonne National Laboratory } \\ \text { ASME } & \text { American Society of Mechanical Engineers } \\ \text { B\&PV } & \text { Boiler and Pressure Vessel } \\ \text { DOE } & \text { Department of Energy } \\ \text { EPP } & \text { Elastic - Perfectly Plastic } \\ \text { ORNL } & \text { Oak Ridge National Laboratory } \\ \text { SMT } & \text { Simplified Model Test }\end{array}$




\section{ACKNOWLEDGMENTS}

The research was sponsored by the U.S. Department of Energy, under contract No. DE-AC05-

00OR22725 with Oak Ridge National Laboratory (ORNL), managed and operated by UT-Battelle, LLC, and under Contract No. DE-AC02-06CH11357 with Argonne National Laboratory (ANL), managed and operated by UChicago Argonne, LLC. Programmatic direction was provided by the Office of Advanced Reactor Technologies (ART) of the Office of Nuclear Energy (NE).

Technical support from C. Shane Hawkins of ORNL for running the experiments is acknowledged. Seth T. Baird of ORNL provided supports in specimen preparations. The authors thank Robert Jetter of R.I. Jetter Consulting for discussions on the EPP and SMT design methodologies. The time spent by Lianshan Lin, Hong Wang and Edgar Lara-Curzio of ORNL in reviewing this report is greatly appreciated. 


\begin{abstract}
This report summarizes the results from experiments performed in FY18 on Gr. 91 steel (heat 30176). The testing of Gr. 91 has technical significance because, currently, it is the only approved material for Class A construction in ASME Section III Division 5 that is strongly cyclic softening. The focus of this investigation is the effect of pre-cyclic loading history on the responses of Gr. 91 under key feature testing with Simplified Model Test (SMT) creep fatigue and two-bar thermal ratchet loading. For the presoftened SMT, the SMT life reduction ratio was found to be approximately the same as the pre-softening fatigue damage ratio. The pre-softening also affected the ratchet behavior for the SMT specimens. Under the same two-bar thermal ratchet test conditions, the pre-softened specimens showed faster ratchetting rates or larger accumulated strains than those without pre-softening history. In addition, results from previous uniaxial mechanical tests in support of the viscoplastic material model development for Gr. 91 are summarized, and the new results from thermomechanical testing at high temperature range are reported.
\end{abstract}




\section{INTRODUCTION}

The simplified design rules in Division 5 Appendix HBB-T of ASME's Boiler and Pressure Vessel Code for the evaluation of strain limits and creep-fatigue damage are based on elastic analysis. The technical basis of the simplified design methods was developed with the tacit assumption that plastic and creep deformation are uncoupled. When such conditions are not met, e.g., at higher temperatures, where it is not feasible to decouple plasticity and creep deformation, the technical basis of the simplified design rules is no longer valid.

The Elastic - Perfectly Plastic (EPP) design methods have already been developed and qualified for 304H and 316H stainless steel in ASME Sec. III Div. 5 applications via two approved code cases, strain limits code case (N-861) and EPP creep-fatigue code case (N-862) to address the deficiency in the simplified design rules. The EPP methods are valid for the full range of allowable temperatures, even when plasticity and creep are coupled. Further, the EPP cyclic service methodology greatly simplifies the design evaluation procedure by eliminating the need for stress classification and the restrictions on geometry or loading.

Grade 91 steel is currently an approved material for Class A construction in ASME Section III Division 5, Subsection HB, Subpart B. Qualification of Grade 91 steel for the EPP strain limits and creep-fatigue evaluations is a high priority R\&D item of the ASME Code committee responsible for Division 5 . The qualification of the EPP methods for Grade 91 steel have technical significance because currently this steel is the only approved material for Division 5 Class A construction that is strongly cyclic softening.

During FY18, key feature experiments continued on Grade 91 steel as part of an effort to qualify the EPP methods for this material. The focus of the investigation is the effect of pre-cyclic loading history on the responses of Grade 91 under key feature testing with Simplified Model Test (SMT) creep fatigue and two-bar thermal ratchet loading. The basic concept of the SMT methodology was to provide an alternative approach for evaluating creep-fatigue damage of actual structures with a suitably sized specimen that models the actual structural stress and strain redistribution (Jetter, 1998, Wang, et al., 2015). The SMT creep fatigue evaluation approach is simpler to implement than the current complex rules and it is applicable to the full temperature range from ambient conditions to the very high temperature creep regime. Thus, the SMT results can be used to verify the conservatism of the EPP creep-fatigue evaluation methodology. In the two-bar thermal ratchet experiments, the two bars can be viewed as elements taken out of a tubular component inner and outer walls, respectively. The bars are loaded with two coupled servo-controlled testing machines with the bounding conditions to achieve the key features of the two-bar representation of actual component behavior (Wang, et al., 2013). The two-bar thermal ratchet experiments were designed to verify the procedure for evaluating EPP strain limits at very high temperatures. Since the stresses and strains can be measured for both key feature experiments, the information obtained from these key feature tests can be used to verify the material constitutive equations. In FY18, additional thermomechanical fatigue experiments were designed to support parallel efforts at the Argonne National Laboratory (ANL) on the development of a viscoplastic material model for Grade 91. 


\section{EXPERIMENTAL DETAILS}

\subsection{MATERIAL}

The material used in this report was obtained from a Gr. 91 plate (heat 30176), which was manufactured by Carpenter Technology Corporation in the early 1980s, has been preserved at ORNL as an archival material. ORNL technical report ORNL-6303 documented the chemical composition of this plate which is listed in Table 1 below. It is noted that the silicon content is $0.11 \%$, lower than the ASME SA-387 specification of $0.2-0.5 \%$. This plate was characterized for its mechanical properties and the data were used as reference data for the Gr. 91 development program.

Table 1. Chemical compositions of Gr. 91 plate with heat number 30176 (weight \%)

\begin{tabular}{c|c|c|c|c|c|c|c|c|c|c}
\hline $\mathbf{C}$ & $\mathbf{P}$ & $\mathbf{S i}^{*}$ & $\mathbf{N i}$ & $\mathbf{M n}$ & $\mathbf{N}$ & $\mathbf{T i}$ & $\mathbf{S n}$ & $\mathbf{V}$ & $\mathbf{F e}$ & $\mathbf{A s}$ \\
\hline 0.081 & 0.010 & 0.11 & 0.09 & 0.37 & 0.055 & 0.004 & $<0.001$ & 0.209 & balance & 0.001 \\
\hline $\mathbf{Z r}$ & $\mathbf{S}$ & $\mathbf{C r}$ & $\mathbf{C o}$ & $\mathbf{M o}$ & $\mathbf{A l}$ & $\mathbf{W}$ & $\mathbf{C u}$ & $\mathbf{N b}$ & $\mathbf{B}$ & \\
\hline$<0.001$ & 0.003 & 8.61 & 0.010 & 0.89 & 0.007 & $<0.01$ & 0.04 & 0.072 & $<\mathbf{0 . 0 9}$ & \\
\hline
\end{tabular}

*Note: heat 30176 is low in Si content.

The Gr. 91 plate was hot forged followed by hot rolling. The nominal thickness of the plate is $25.4 \mathrm{~mm}$ (or 1-inch). A section measuring $1550 \mathrm{~mm}$ x $635 \mathrm{~mm}$ was cut off from this plate as the supply material for specimen machining. This section of plate material was normalized at $1050^{\circ} \mathrm{C}$ for one hour and then tempered at $760^{\circ} \mathrm{C}$ for 2 hours followed by air cooling. The heat treatment was performed by Bodycote Thermal Processing, Inc. in Morristown, Tennessee. The microstructure of the plate, which was characterized and reported in ORNL technical report ORNL/TM-2017/388, was shown to have typical tempered martensitic features with no untempered martensite. The Vickers hardness value was 227 $\mathrm{kg} / \mathrm{mm}^{2}$, which is within the range of $195-265 \mathrm{Hv}$ specified in SA-387.

\subsection{SPECIMENS AND EXPERIMENTS}

\subsubsection{Specimen geometries}

All the specimens used in this study were machined along the plate rolling direction. The specimen geometries used in the report are the same as what was used in previously by Wang, et al. (2017a).

The standard creep-fatigue specimen has 6.35 mm (0.25-inch) gage diameter as shown in Fig. 1.

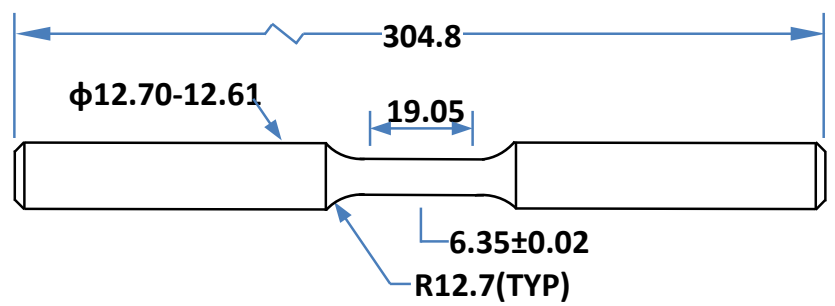

Fig. 1. Standard creep-fatigue specimen geometry. Units are in mm.

The combined effect of elastic follow-up and stress concentration is the key principle in the original SMT specimen design. The Type 1 SMT specimen is designed to have the combined effect and its geometry is shown in Fig. 2. The diameters of the necked test section and the thicker driver section were designed to 
have a cross-sectional area ratio of 1:2. The control length for the applied displacement was $127 \mathrm{~mm}$ (5inch) to achieve the designated elastic follow-up. The $6.35 \mathrm{~mm}$ (0.25-inch) transition radius inside the gage section produces a stress intensification factor of 1.37 .

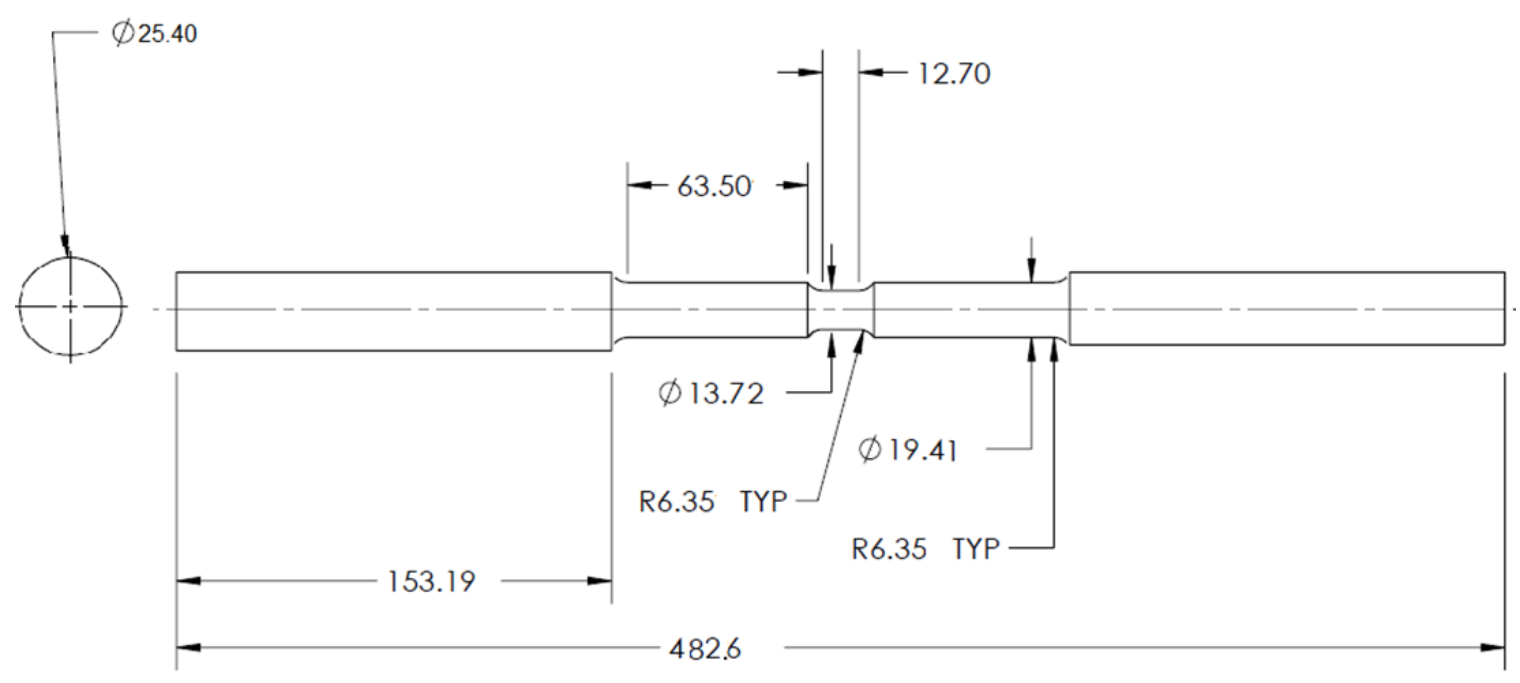

Fig. 2. Type 1 SMT solid bar specimen geometry. Units are in $\mathrm{mm}$.

\subsubsection{Key feature mechanical testing}

\subsubsection{Type 1 SMT Creep Fatigue on pre-softened Gr. 91}

Prior to the Type 1 SMT creep fatigue testing, pre-softening cycles were introduced to the specimen. The specimen was fatigue loaded under strain control with fully reversed triangular waveform for 170 cycles. The pre-cyclic loading was performed at $600^{\circ} \mathrm{C}$ at $1 \%$ strain range with $\mathrm{R}$ ratio of -1 . The strain rate for the cyclic loading was $1 \mathrm{E}-3 \mathrm{~s}^{-1}$. The loading profile is schematically shown in Fig. 3a. The $1 \%$ strain range was controlled via an extensometer placed inside the uniform section of the necked test section. The 170 cycles correspond to $28 \%$ of the fatigue life of this Gr. 91 material under this testing condition.

After the pre-softening procedure, the specimen was subjected to SMT creep fatigue test at $650{ }^{\circ} \mathrm{C}$. The testing parameters were the same as previous test \#29 in Wang, et al. (2016a) where the results for an unsoftened Type 1 Gr. 91 SMT specimen were reported. For this Type 1 SMT experiment, the 127 mm (5inch) effective length for the applied end displacement include the $12.7 \mathrm{~mm}$ (0.5-inch) necked test section, $11.2 \mathrm{~mm}$ (0.44-inch) transition region and $104.1 \mathrm{~mm}$ (4.1-inch) driver section. The accuracy in end displacement control is crucial for the accurate control of the elastic follow up and it is achieved by testing the specimen under strain-control mode using a customized extensometer with $127 \mathrm{~mm}$ (5-inch) gage length. In the necked down test section of the SMT specimen, there is a $12.7 \mathrm{~mm}$ (0.5-inch) uniform axial length for local strain measurement with an extensometer of $10.2 \mathrm{~mm}$ (0.4-inch) gage length. The measured axial strains were used to generate the hysteresis loops along with the applied stresses. The applied end-displacement profile is schematically shown in Fig. 3b. There was a 600 second hold time at the minimum displacement. The applied end-displacement amplitude was $0.114 \mathrm{~mm}$ (4.5 mil), corresponding to an elastically calculated strain range of $0.3 \%$ in the necked test section. 


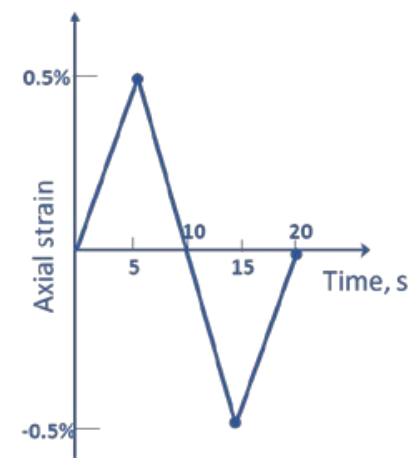

(a)

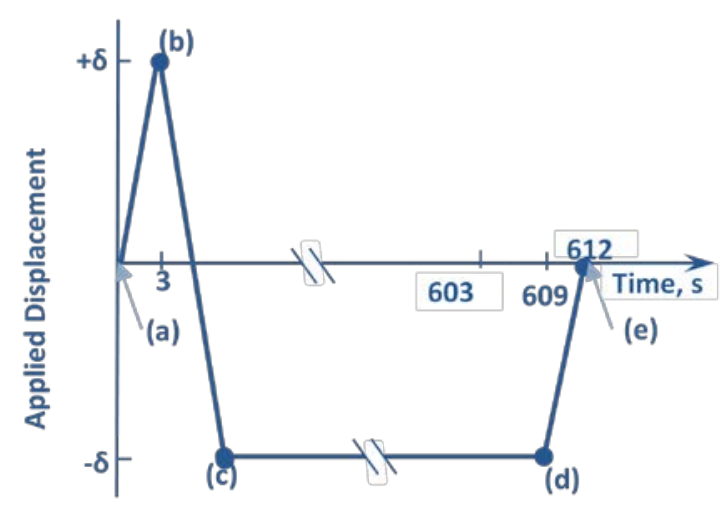

(b)

Fig. 3. Applied loading profile for one cycle of pre-cyclic softening (a) and SMT creep-fatigue testing with compression hold (b)

\subsubsection{Two-bar thermal ratcheting test on pre-softened Gr. 91}

Standard creep fatigue specimens with the geometry shown in Fig. 1 were used for the two-bar thermal ratchet experiments. Prior to the two-bar thermal ratchet testing, the specimens were pre-cyclic fatigue loaded for 150 cycles at $600{ }^{\circ} \mathrm{C}$ at $1 \%$ strain range with fully reversed triangular loading profile to introduce the pre-cyclic softening effect. The loading strain rate was $1 \mathrm{E}-3 \mathrm{~s}^{-1}$. The loading profile is the same as Fig. 3a. The 150 cycles are equivalent to approximately $25 \%$ of the fatigue life under this test condition.

The bars were loaded with two coupled servo-controlled testing machines for the thermal ratchet experiments. The details of the two-bar thermal ratchet experiment setup were explained in Wang et al. (2013). The control logic allows the two bars to have equal strain, yet the total applied load shared by the two bars is kept constant throughout the duration of the test. The temperature profile shown in Fig. 4. was applied to the two bars. The time delay introduced between (1) and (2) defines the temperature difference in the two bars. The thermal strains introduced to the specimens are a function of the time delay, the heating and cooling rates, and the total temperature difference. The specimens were heated and cooled at 
a rate of $30{ }^{\circ} \mathrm{C} / \mathrm{min}$, corresponding to an equivalent strain rate of $2.2 \mathrm{E}-6 \mathrm{~s}^{-1}$ based on the thermal expansion and the heating/cooling rates. Table 2 summarizes the parameters used for the two-bar experiments on these pre-softened specimens. The testing temperature range of 350 to $650{ }^{\circ} \mathrm{C}$ and the change in loading conditions was performed at $350{ }^{\circ} \mathrm{C}$ without unloading the specimens to zero load from the previous condition. Two-bar thermal ratchet experiments were performed with different combinations of total load levels and time delays for direct comparison with the previous test \#30 (refer to Wang et al. 2017a, 2017b) on un-softened Gr. 91.

Table 2. Parameters of the two-bar experiment on pre-softened Gr. 91

\begin{tabular}{l|l}
\hline Material & Gr. 91(heat 30176), pre-softened \\
\hline Specimen diameter & $6.35 \mathrm{~mm}(0.25$-inch) \\
\hline Temperature range & 350 to $650^{\circ} \mathrm{C}$ \\
\hline hold time (4) to (5) & $60 \mathrm{~min}$ \\
\hline $\begin{array}{l}\text { Heating and cooling rate } \\
\text { (1) to 3), (2) to (4) and (5) to 6) }\end{array}$ & $30^{\circ} \mathrm{C} / \mathrm{min}$ \\
\hline $\begin{array}{l}\text { time delay, (1) to (2) } \\
\text { Applied total load }\end{array}$ & From $3 \mathrm{~min}$ to $10 \mathrm{~min}$ \\
\hline
\end{tabular}

Note: see Fig. 4 for additional information

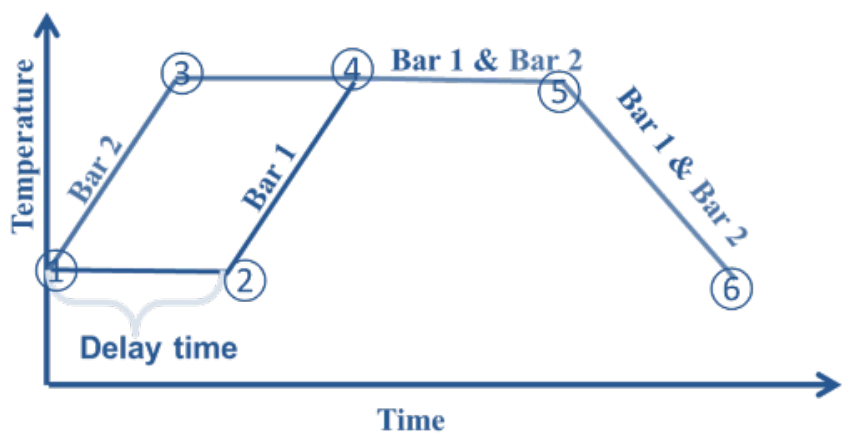

Fig. 4. Two-bar thermal cycle.

Consistent with the preceding work by Wang et al. (2013, 2014, 2015, 2016b, 2017a), the ratchet strain is defined as the difference between the mechanical strain at a time point in a thermal cycle and that at the same time point in the reference cycle. When the same point in the thermal cycle is selected, the amount of ratchet strain calculated based on the total strain is the same as that calculated based on the mechanical strain. In this study, the ratcheting strains were calculated from the maximum total strains of each cycle, and they were approximately the same values as those calculated based on the minimum total strains. The reference cycle was cycle \# 10 under each condition. The test results were extrapolated to obtain the accumulated ratchet strains at 350 hours to provide information to our parallel theoretical studies on strain limits of Gr. 91. 


\subsubsection{Thermomechanical fatigue to support the viscoplastic material model development}

The thermomechanical fatigue experiment was performed at a temperature range of 500 to $600{ }^{\circ} \mathrm{C}$ with heating and cooling rates of $10^{\circ} \mathrm{C} / \mathrm{min}$ using an igniter heater furnace. This test was designed to validate the viscoplastic material model developed at ANL. The temperature profile was controlled by a LabView program. Prior to the thermomechanical fatigue test, the specimen was thermally cycled at zero load to collect thermal expansion measurement data. Thermomechanical fatigue was conducted according to standard test method ASTM-2368-10. It was under strain control with straining cycles that are 180 degrees out-of-phase with the thermal cycles, i.e., anti-phase thermomechanical fatigue. For this experiment, the total strain was controlled to be zero and the starting temperature was $500^{\circ} \mathrm{C}$. The relationship between the strain and the temperature for this anti-phase thermomechanical fatigue is schematically shown in Fig. 5. The testing parameters are listed in Table 3.

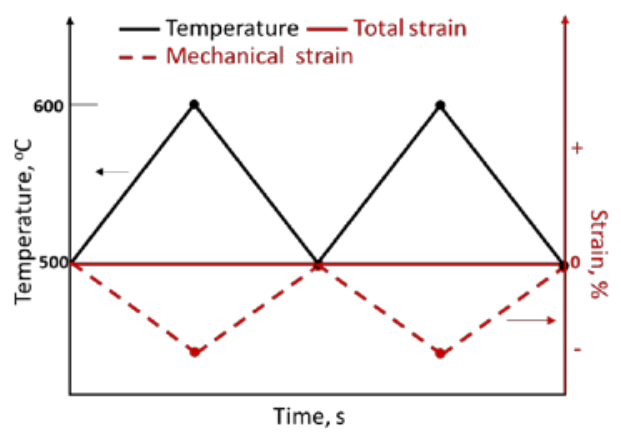

Fig. 5. Schematics of the anti-phase thermomechanical fatigue for two cycles

Table 3. Test parameters for thermomechanical experiment on Gr. 91 (heat 30176)

\begin{tabular}{l|l}
\hline Test temperature range & $500^{\circ} \mathrm{C}$ to $600{ }^{\circ} \mathrm{C}$ \\
\hline Specimen diameter & $6.35 \mathrm{~mm}(0.25$-inch $)$ \\
\hline Controlled total strain amplitude & $0 \%$ \\
\hline Starting temperature & $500^{\circ} \mathrm{C}$ \\
\hline Heating and cooling rates & $10^{\circ} \mathrm{C} / \mathrm{min}$ \\
\hline Temperature mechanical strain phase angle & $180^{\circ}$, i.e., anti-phase thermomechanical fatigue \\
\hline Experiment control mode & Strain control \\
\hline
\end{tabular}




\section{RESULTS AND DISCUSSION}

\subsection{RESULTS FROM KEY FEATURE MECHANICAL TESTING}

\subsubsection{Effect of pre-cyclic softening on Type 1 SMT creep fatigue}

The SMT creep-fatigue test results at $650{ }^{\circ} \mathrm{C}$ on Gr. 91 (heat 30176) with pre-softening cycles are summarized in Table 4. For comparison purposes, the previous Type 1 SMT creep-fatigue evaluation results on the Gr. 91 (heat 30176) without pre-softening cycles (test \# 29 in Wang et al. 2016a) are also listed in the table. Both tests had the same nominal elastically calculated strain range of $0.3 \%$ inside the necked test section. The measured actual strain ranges for both tests are higher than the elastically calculated strain range with the pre-softened SMT specimen showed slightly higher strain range. The cycles to failure were reduced by $27 \%$ when pre-softening cycles were introduced, and this reduction factor is almost the same as the fatigue damage ratio introduced by the pre-cyclic softening.

Table 4. Summary of the SMT creep-fatigue results

\begin{tabular}{c|c|c|c|c|c|c|c|c|c}
\hline \multirow{2}{*}{ Material } & $\begin{array}{c}\text { Test } \\
\text { No. }\end{array}$ & $\begin{array}{c}\text { Amplitude, } \boldsymbol{\delta} \\
\text { value, mil }\end{array}$ & $\begin{array}{c}\text { Elastically } \\
\text { calculated } \\
\text { strain range } \\
\text { inside gage }\end{array}$ & $\begin{array}{c}\text { Hold } \\
\text { time } \\
\text { (sec) }\end{array}$ & $\begin{array}{c}\text { Loading profile } \\
\text { Initial } \\
\text { strain } \\
\text { range }\end{array}$ & $\begin{array}{c}\text { Test } \\
\text { temperature } \\
\left({ }^{\mathbf{0}} \mathbf{C}\right)\end{array}$ & $\begin{array}{c}\text { Life time } \\
\text { (hr) }\end{array}$ \\
\hline $\begin{array}{c}\text { Gr. 91 plate } \\
\text { (heat 30176) }\end{array}$ & $\# 29$ & 4.5 & $0.296 \%$ & 600 & $\begin{array}{c}\text { Compression ture } \\
\text { hold }\end{array}$ & $0.33 \%$ & 650 & 187 & 1100 \\
\cline { 2 - 10 } & $\# 42$ & 4.5 & $0.296 \%$ & 600 & $\begin{array}{c}\text { Compression } \\
\text { hold }\end{array}$ & $0.38 \%$ & 650 & 136 & 800 \\
\hline
\end{tabular}

Plots of the measured average strain and strain range inside the necked test section, the maximum (tension) and minimum (compressive) stresses as a function of cycles and a picture of the failed specimens are compared in Fig. 6 for the SMT on Gr. 91 with (test \#42) and without pre-cyclic softening (test \#29). The response of the material to SMT creep fatigue loading is very complex, and the comparison shows that the ratcheting behavior was significantly different when the pre-softening cycles were introduced. The original SMT on unsoftened Gr. 91 showed tensile ratcheting of more than 5\% of the average axial strain, whereas the test with pre-softening cycles showed initial tensile ratcheting with a much slower ratchetting rate but switched to compression ratchetting after about 550 cycles. The accumulated ratchet strain was tensile for the specimen without pre-cycles but compressive for the presoftened specimen. Post-test observations on the failed specimens show that the SMT test without precyclic loading had significant necking at the center of the test section where a major crack was also observed in addition to the cracking at the root of the transition radius. The specimen for SMT testing with pre-softening cycles was found to be slightly barreled after testing with the major failure locations only appeared at the root of the transition radius. The failure behavior is consistent with the measured accumulated strain for both specimens in that the accumulated strain in the pre-softened specimen was compressive and tensile for the specimen without pre-cycles.

The hysteresis loops and the normalized stress relaxation curves for cycle \# 5, \# 100 and \# 500 are compared in Fig. 7 and Fig. 8 for the SMT with pre-softening cycles (test \#42) and unsoftened SMT (test \# 29). The faster ratcheting for the unsoftened SMT is evidently shown in Fig. 7. Due to the cyclic softening effect, the stress relaxes more significantly when they reached cycle \#500 although the cycle \#5 and 100 did not show significant differences for both specimens. Comparing the normalized stress relaxation curves for the two specimens, interestingly, the relative amount of stress relaxation is shown to be insensitive to the pre-cyclic loading in that the both specimens showed stress relaxation to about $70 \%$ peak stress for cycle \# 5 and 100 and about $50 \%$ of the peak stress for cycle \#500. 


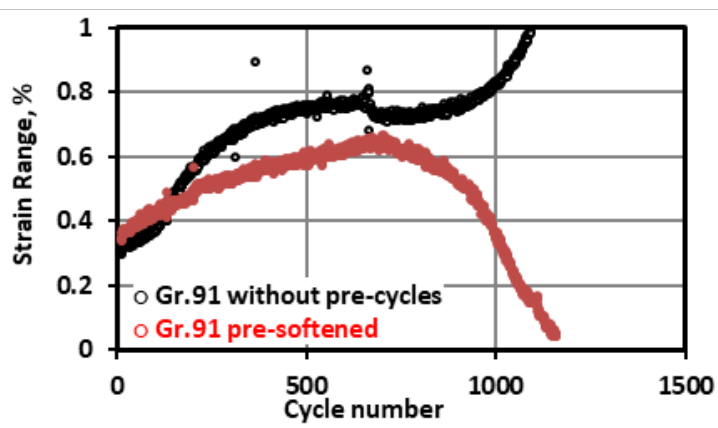

(a) Strain range

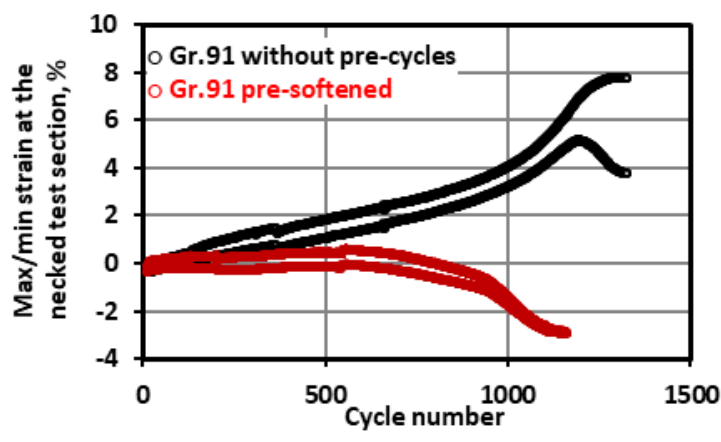

(c) ratcheting strain

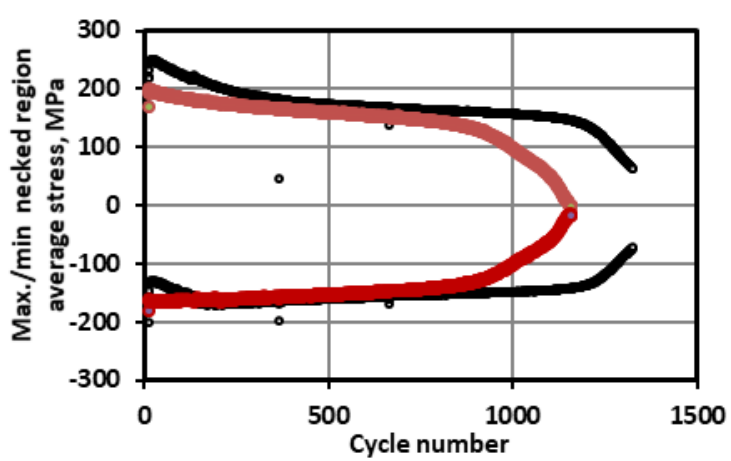

(b) Max/Min stresses

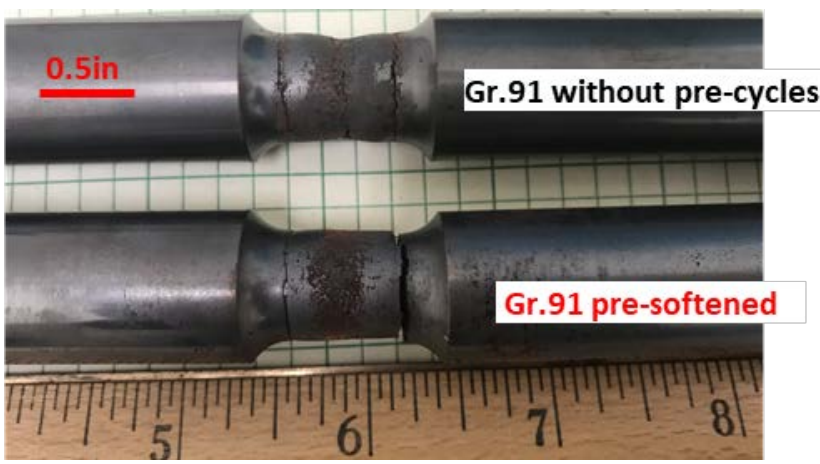

(d) failed specimens

Fig. 6. Comparison of the Type $1 \mathrm{SMT}$ creep -fatigue test results at $650^{\circ} \mathrm{C}$ on $\mathrm{Gr} .91$ (heat 30176$)$ with and without pre-softening cycles. The 170 pre-softening cycles were introduced to the specimen at $600{ }^{\circ} \mathrm{C}$ at $1 \%$ strain range under fully reversed pure fatigue loading

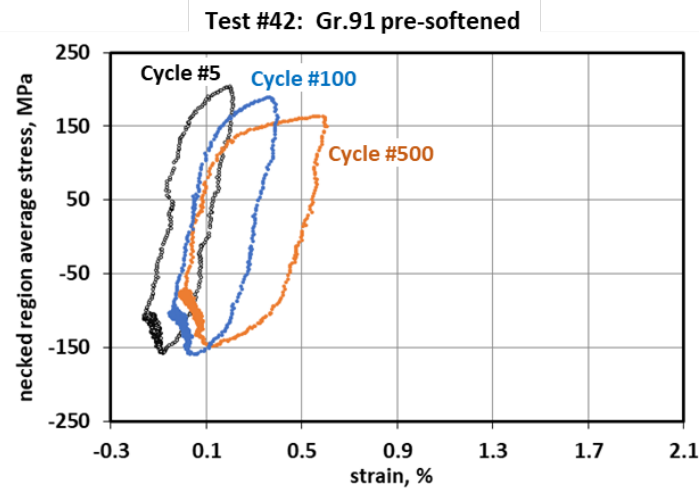

(a)

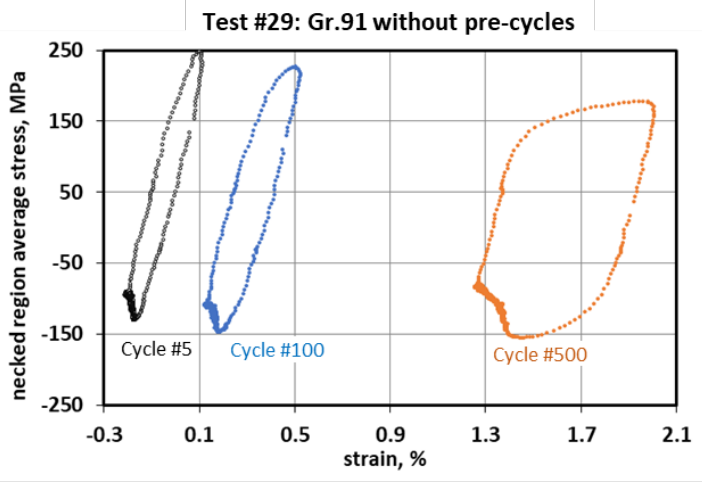

(b)

Fig. 7. Representative hysteresis loops for the Type $1 \mathrm{SMT}$ creep -fatigue test at $650^{\circ} \mathrm{C}$ on $\mathrm{Gr} .91$ (heat 30176) with pre-softening cycles (a) and without pre-softening (b). The 170 pre-softening cycles were introduced to the specimen at $600{ }^{\circ} \mathrm{C}$ at $1 \%$ strain range under fully reversed pure fatigue loading. 


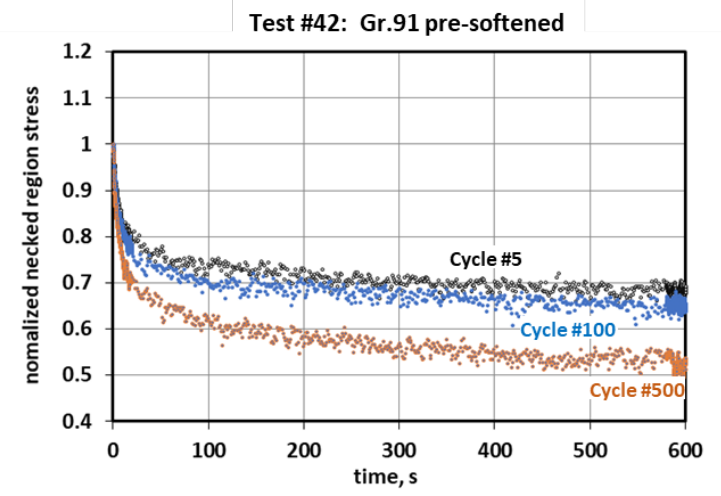

(a)

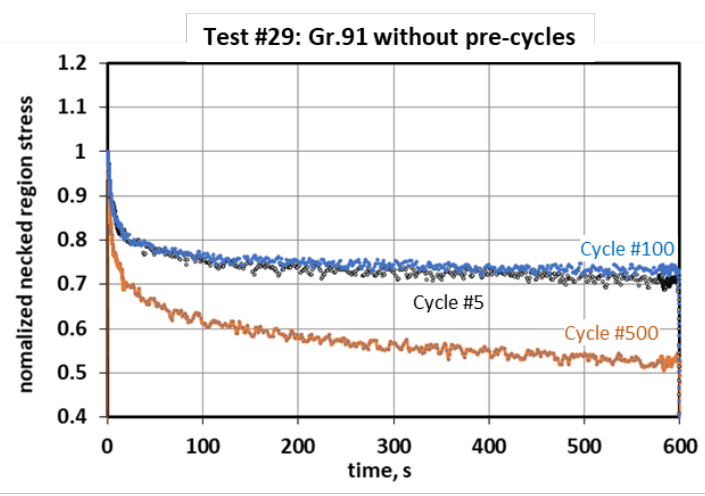

(b)

Fig. 8. Representative normalized stress relaxation curves for the Type 1 SMT creep -fatigue test at $650^{\circ} \mathrm{C}$ on Gr. 91 (heat 30176) with pre-softening cycles. The 170 pre-softening cycles were introduced at $600{ }^{\circ} \mathrm{C}$ at $1 \%$ strain range under fully reversed pure fatigue loading.

\subsubsection{Two-bar thermal ratchet test results on pre-softened Gr. 91}

The current EPP strain limits evaluation in ASME B\&PV Code Case N-861 uses the pseudo-yield stress which is based on the isochronous curves and the yield strength values. These properties were developed from tests performed on specimens without any pre-cyclic loading history. For Gr. 91, it is known to have softening behavior under cyclic loading, and it shows higher creep rates for specimens with pre-softening history. The pseudo-yield stresses developed from tests on unsoftened material will be higher values than those with pre-softened cyclic loading. Therefore, EPP strain limits evaluation based on the pseudo-yield stresses of unsoftened material could potentially show unconservative results. In a parallel study, numerical simulations were performed by Messner, et al, (2017, 2018a) at ANL on EPP strain limits evaluation of pre-softened Gr. 91, and a simplified procedure was formulated to modify the existing ASME code isochronous curves to account for the softening without performing large number of tests on pre-softened specimens. In this reporting period, two-bar thermal ratcheting tests were performed on presoftened Gr. 91 specimens (heat 30176) at ORNL. The purpose of this test is to evaluate the effect of precyclic softening on the two-bar thermal ratchet behavior for Gr. 91 and verify the modified design procedure for EPP strain limits evaluation.

The pre-softened specimens were thermally cycled on two coupled servo-hydraulic test machines between 350 and $650^{\circ} \mathrm{C}$ under two-bar thermal ratchet condition. The temperature profile used for the thermal cycles is shown in Fig. 4, where Bar 1 is defined as the one with a time delay in the heating segment. An example of the thermal profile with a 6-minute delay for one cycle is shown in Fig. 9 below for a testing condition. 


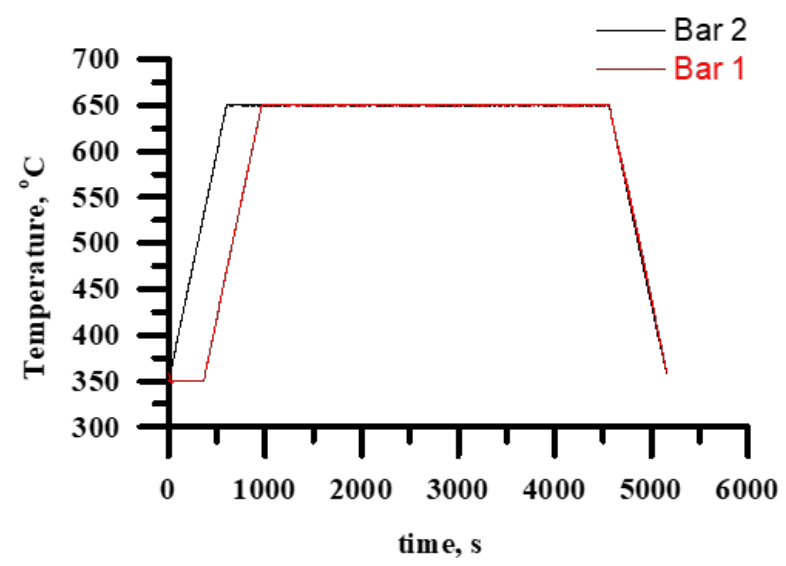

Fig. 9. One cycle of the thermal profile with 6 minutes delay for the two-bar test

The two-bar thermal ratchet tests at different applied mean stresses and time delays were performed on these same two bars with sequential test numbers of T31-1 to T31-9. The test parameters and results for these testing conditions are summarized in Table 5. For the test number T31-9, there was a glitch from instrumentation malfunction that caused the heater furnace on bar 1 to shut down during cycle \#36, therefore, only the first 35 cycles are valid and used for the reporting in the table.

Table 5. Summary of the two-bar thermal ratcheting experiments for temperature range of 350 to $650^{\circ} \mathrm{C}$ on pre-softened Gr. 91 (heat 30176).

\begin{tabular}{l|c|c|c|c|c}
\hline Test No. & T31-1 & T31-2 & T31-3 & T31-4 & T31-5 \\
\hline Applied mean stress, MPa & $-7.7 \pm 1$ & $50.1 \pm 1.1$ & $65.1 \pm 1$ & $82.9 \pm 1$ & $-29.1 \pm 1.3$ \\
\hline Time delay (minutes) & 10 & 10 & 10 & 10 & 6 \\
\hline Nominal total load, N (lbs) & $-445(-100)$ & $3115(700)$ & $4005(900)$ & $5118(1150)$ & $1180(-400)$ \\
\hline Total number of cycles tested & 34 & 45 & 35 & 14 & 33 \\
\hline Ratcheting rate (per cycle), \% & -0.0064 & 0.0013 & 0.0055 & 0.039 & -0.021 \\
\hline Initial stress on Bar 1, MPa & -4.17 & -20.5 & 41.0 & 37.7 & -40.4 \\
\hline Initial stress on Bar 2, MPa & -10.97 & 118.7 & 88.2 & 125.5 & -15.5 \\
\hline Initial residual total strain, \% & -0.008 & -0.43 & -0.21 & 0.053 & 0.68 \\
\hline Reference cycle No. & 10 & 10 & 10 & 10 & 10 \\
\hline Reference cycle minimum total strain, \% & -0.292 & -0.28 & -0.086 & 0.55 & 0.15 \\
\hline Stress range per cycle for Bar 1, MPa & $307 \pm 3.9$ & $289.7 \pm 2.7$ & $289.2 \pm 6.8$ & $271.0 \pm 1.5$ & $252.1 \pm 2.0$ \\
\hline Stress range per cycle for Bar 2, MPa & $310.5 \pm 3.1$ & $294.0 \pm 2.7$ & $293.4 \pm 7.2$ & $275.0 \pm 1.9$ & $256.75 \pm 2.2$ \\
\hline
\end{tabular}


Table 5 continued

\begin{tabular}{l|c|c|c|c}
\hline Test No. & T31-6 & T31-7 & T31-8 & T31-9 \\
\hline Applied mean stress, MPa & $65.3 \pm 1.2$ & $14.4 \pm 0.6$ & $14.4 \pm 0.7$ & $-7.6 \pm 0.7$ \\
\hline Time delay, min & 6 & 10 & 6 & 3 \\
\hline Nominal total load, N (lbs) & $4005(900)$ & $890(200)$ & $890(200)$ & $-445(-100)$ \\
\hline Total number of cycles tested & 33 & 33 & 33 & 35 \\
\hline Ratcheting rate (per cycle), \% & 0.0107 & -0.0014 & -0.00058 & -0.0003 \\
\hline Initial stress on Bar 1, MPa & 122.8 & 20.6 & 25.8 & -48.1 \\
\hline Initial stress on Bar 2, MPa & 6.4 & 8.7 & 2.0 & 32.8 \\
\hline Initial residual total strain, \% & -0.30 & 0.34 & 0.12 & 0.11 \\
\hline Reference cycle No. & 10 & 10 & 10 & 10 \\
\hline Reference cycle minimum total strain, \% & 0.096 & 0.167 & 0.139 & 0.096 \\
\hline Stress range per cycle for Bar 1, MPa & $253.4 \pm 1.3$ & $263.2 \pm 1.3$ & $241.0 \pm 1.1$ & $182.8 \pm 2.3$ \\
\hline Stress range per cycle for Bar 2, MPa & $258.6 \pm 1.4$ & $265.2 \pm 1.3$ & $243.0 \pm 1.1$ & $184.9 \pm 2.2$ \\
\hline
\end{tabular}

The ratchet behavior of pre-softened Gr. 91 was compared to the un-softened test in Fig. 10 for the first four conditions in the test sequence. The ratcheting rates for all four combined total loads of $-445 \mathrm{~N}$ (or $-100 \mathrm{lbs}$ ), $3115 \mathrm{~N}$ ( or $700 \mathrm{lbs}$ ), $4005 \mathrm{~N}$ ( or $900 \mathrm{lbs}$ ) and $5118 \mathrm{~N}$ ( or 1150 lbs) and 10-minute delay were faster for the specimens with pre-softening cycles.

The faster ratcheting rates correspond to a larger accumulated strain for the same evaluation time duration. The ratchet strains for the unsoftened and pre-softened Gr. 91 were extrapolated to 350 hrs for tests with 10-minutes time delay and under a range of combined total load, and the results are compared in Fig. 11. Under all tested conditions, the accumulated ratchet strains are larger for pre-softened Gr. 91. In this plot, the combined total loads with accumulated ratchet strains exceeding the $\pm 1 \%$ strain limits are identified by the arrows. The pre-softened Gr. 91 shows a much narrower range of applied total load to allow the accumulated ratchet strain to be within the $\pm 1 \%$ strain limits. 


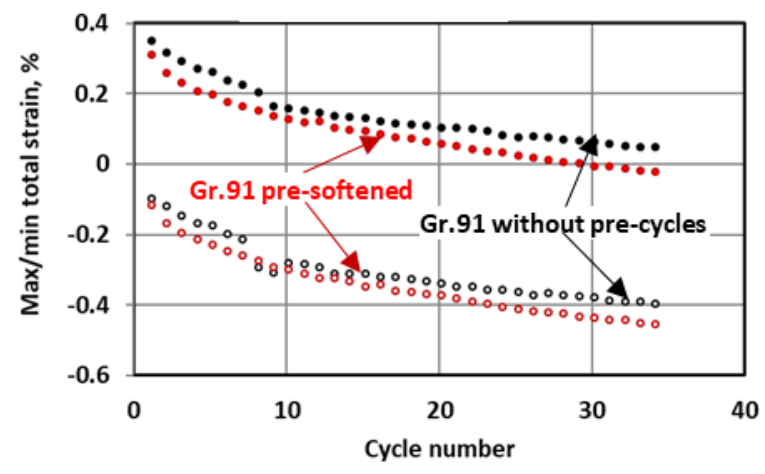

(a)

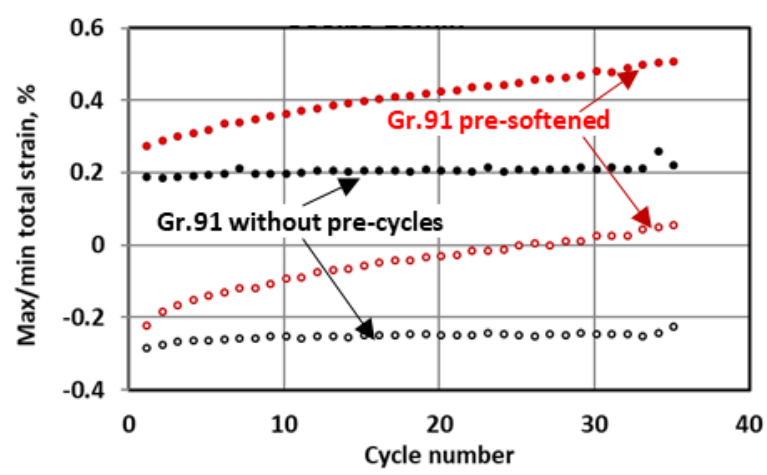

(c)

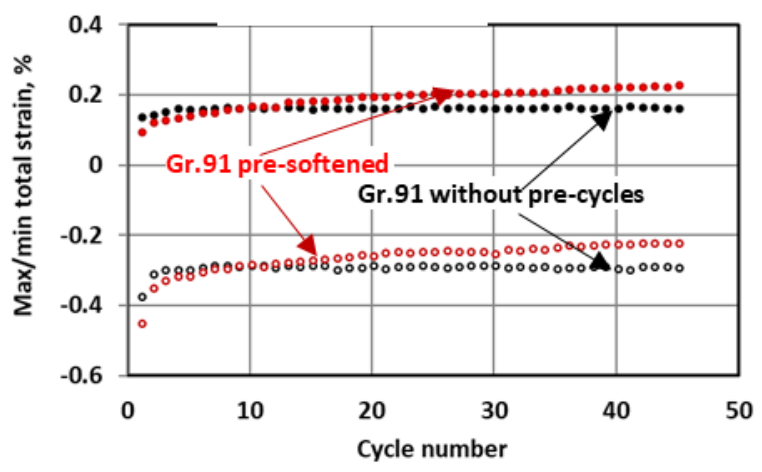

(b)

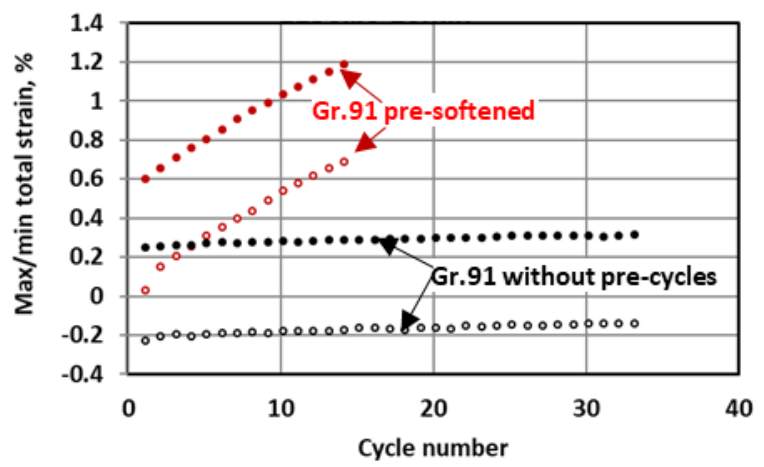

(d)

Fig. 10. Comparison of the two-bar thermal ratcheting behavior of unsoftened Gr. 91 and pre-softened Gr. 91 under combined total load of $-445 \mathrm{~N}(\mathrm{a}), 3115 \mathrm{~N}$ (b), $4005 \mathrm{~N}$ (c) and $5118 \mathrm{~N}$ (d) and with 10 minutes time delay. Open circles are the minimum total strain and the filled circles are the maximum total strain.

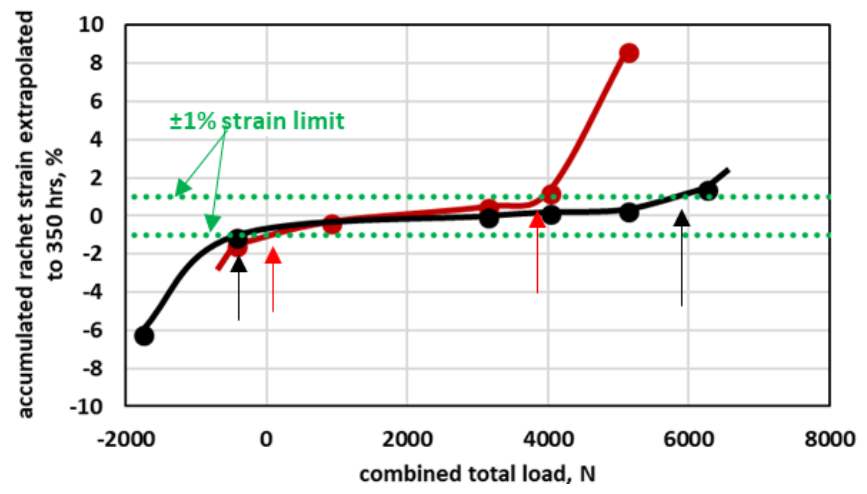

Fig. 11. Comparison of the 350-hr accumulated strains for softened and un-softened Gr. 91 tested with 10-minutes delay under two-bar thermal ratchet condition 


\section{UNIAXIAL MECHANICAL TESTING IN SUPPORT OF VISCOPLASTIC MATERIAL MODEL DEVELOPMENT}

\subsection{SUMMARY OF PREVIOUS TEST RESULTS ON MATERIAL MODEL DEVELOPMENT FOR GR. 91}

The use of the inelastic analysis method is a less restrictive method to evaluate strain limits and creepfatigue damage for Gr. 91. Development of an inelastic analysis method for Gr. 91 steel is an ASME Code committee high priority item. A unified viscoplastic constitutive model for Gr. 91 is developed at ANL to support this task. ASME Code committee plans include incorporation of the Gr. 91 unified viscoplastic model in ASME Division 5, Appendix HBB-Z on inelastic analysis method by the end of 2018. At ORNL, experiments are designed to provide data for calibration and verification of the material constitutive model.

Four types of uniaxial mechanical tests were performed on Gr. 91 (heat 30176) at ORNL in FY17 (Wang, et al., 2017a) to support the viscoplastic material model development at ANL. The results are briefly summarized below.

Cyclic stress-strain curves were generated from room temperature to $566{ }^{\circ} \mathrm{C}$ under fully reversed strain profile with an $1.0 \mathrm{E}-3 \mathrm{~s}^{-1}$ strain rate. Cyclic softening was shown for all the test temperatures at strain ranges larger than $2 \%$. No significant cyclic softening was observed for cycles at low strain range of $0.4 \%$. At temperatures up to $427^{\circ} \mathrm{C}$, the cyclic softening rate increases with increasing strain range. For higher test temperatures between 482 and $566^{\circ} \mathrm{C}$, the cyclic softening rate is similar for all the tested strain ranges of $1.2 \%$ and higher.

The effect of cyclic softening on creep rate was evaluated by introducing strain-controlled cyclic fatigue segments into uniaxial creep tests. The addition of fatigue segments increased the creep rates significantly and shortened creep life. However, the addition of creep segments did not affect its fatigue life under this test condition. The test results are used to establish the reduction factors to adjust the existing ASME Code isochronous curves for Gr. 91 to account for cyclic softening (Messner, et al., 2017, 2018a).

The material strain rate sensitivity was evaluated for Gr. 91 specimens with and without pre-softening cycles. It showed a decreased strain rate sensitivity with prior cyclic softening history. For temperatures of $600^{\circ} \mathrm{C}$ and $538^{\circ} \mathrm{C}$, higher strain rate sensitivity was observed for the test at $600^{\circ} \mathrm{C}$. The test results are used to verify the work performed on Gr. 91 for establishing its temperature upper limits for the ASME Section III, Division 5 design by elastic analysis methods (Messner, et al. 2018b).

The thermomechanical fatigue experiment results on Gr. 91 at large temperature range of 150 to $650^{\circ} \mathrm{C}$ were used to validate the material constitutive model for the temperature depended variables. The model correctly captures the direction and magnitude of the thermal ratcheting and thermal-induced mechanical strain (Messner, 2018c). Additional thermomechanical tests were performed at the higher temperature range at ORNL in FY18 and the results are summarized below.

\subsection{THERMOMECHANICAL TEST RESULTS ON GR. 91 AT $500{ }^{\circ} \mathrm{C}$ TO $600{ }^{\circ} \mathrm{C}$}

The thermal expansion coefficient was determined to be $13.1 \mathrm{E}-6 \mathrm{~mm} / \mathrm{mm} /{ }^{\circ} \mathrm{C}$ using a linear fit of the free expansion curves, which is consistent with previous test on this material. The mechanical strain is calculated by subtracting the thermal expansion from the total strain. The strain range for this test was 
$0.13 \%$. The strain rate was determined by the heating and cooling rate, and it was $2.2 \mathrm{E}-6 \mathrm{~s}^{-1}$. The thermal cycle profile, mechanical strain history, representative hysteresis loops, the maximum and minimum stresses and the stress ranges are plotted in Fig. 12. The specimen was tested for 707 cycles and did not fail at end of the test. The maximum and minimum stresses increased with applied cycles. The stress range did not show significant change over the tested cycles, which is consistent with the previous findings that the Gr. 91 does not show cyclic softening behavior when it is loaded at strain ranges less than $0.4 \%$.

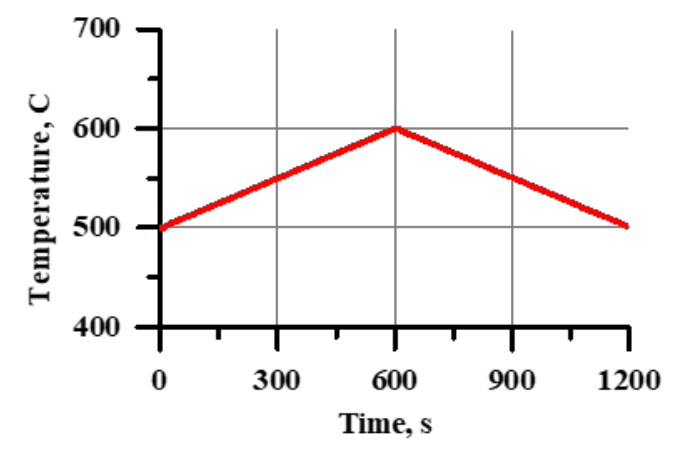

(a) Thermal cycle

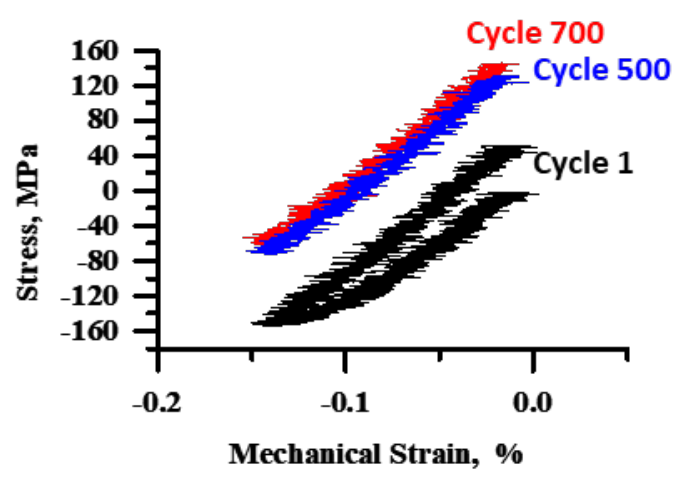

(c) Hysterysis loops

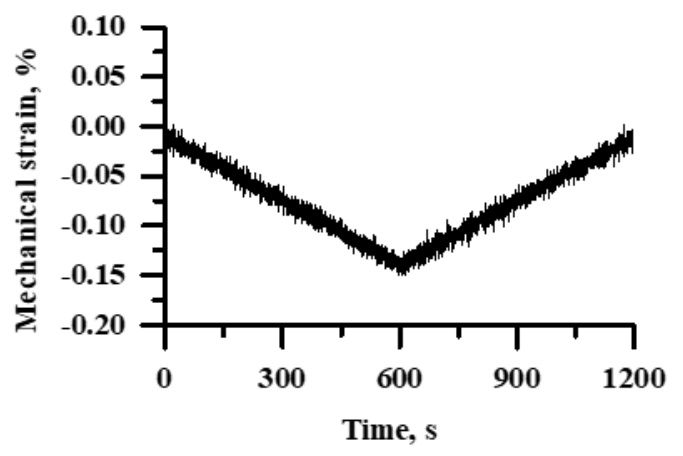

(b) Mechanical strain

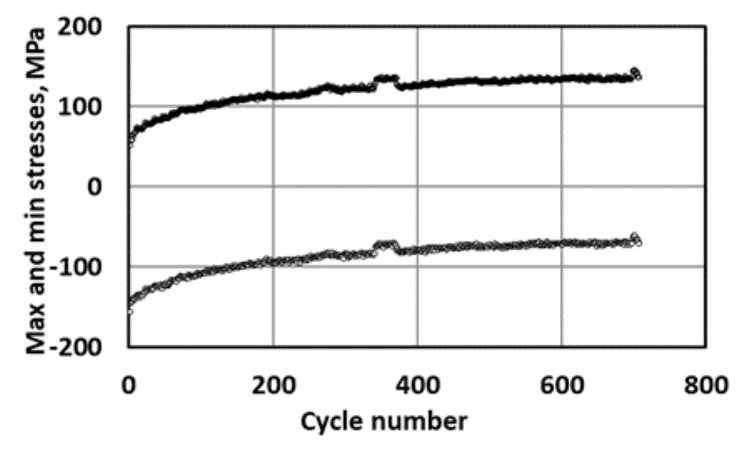

(d) Maximum and minimum stresses

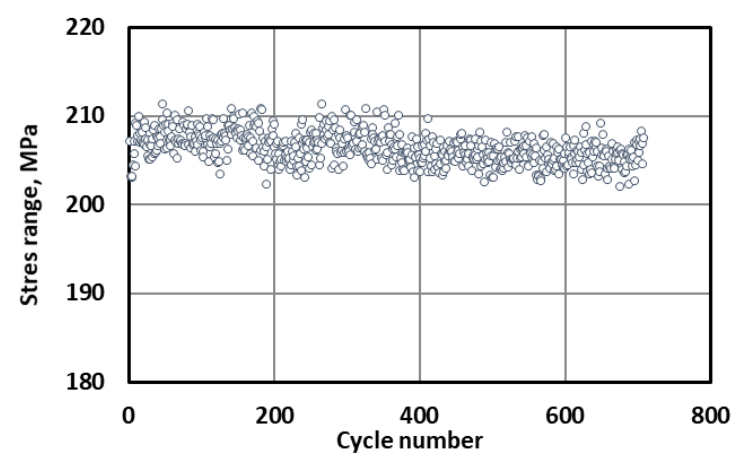

(e) Stress range

Fig. 12. Thermo-mechanical fatigue at temperature range of 500 to $600{ }^{\circ} \mathrm{C}$. 


\section{SUMMARY}

Key feature tests using the Simplified Model Test (SMT) and two-bar thermal ratcheting approaches continued during FY18 to qualify the Elastic - Perfectly Plastic (EPP) design methodologies for Gr. 91 and to support the incorporation of these design rules for Gr. 91 into the ASME Division 5 Code.

The introduction of pre-softening cycles into SMT specimens was shown to reduce the SMT creep fatigue life. The SMT creep fatigue life reduction ratio was found to be approximately the same as the fatigue damage ratio from the pre-cyclic loading. The pre-softened Gr. 91 specimens showed faster ratcheting rates or larger accumulated strains than those without pre-softening history when tested under two-bar thermal ratchet conditions.

In addition, results from previous uniaxial mechanical tests in support of viscoplastic material model development for Gr. 91 are summarized, and additional thermomechanical tests at temperature range of 500 to $600{ }^{\circ} \mathrm{C}$ are reported. All the experimental data on the uniaxial mechanical test were used to calibrate the viscoplastic material model for Gr. 91. 


\section{REFERENCES}

1. ASME B\&PV Code Case N-861 "Satisfaction of Strain Limits for Division 5 Class A Components at Elevated Temperature Service Using Elastic-Perfectly Plastic Analysis”.

2. ASME B\&PV Code Case N-862 "Calculation of Creep-Fatigue for Division 5 Class A Components at Elevated Temperature Service Using Elastic-Perfectly Plastic Analysis Section III, Division 5”.

3. Jetter, R. I., 1998, An Alternate Approach to Evaluation of Creep-Fatigue Damage for High Temperature Structural Design, Vol. 5, American Society of Mechanical Engineers, New York, pp. 199-205.

4. J. R. DiStefano et al., (1985), Summary of Modified 9Cr-1Mo Steel Development Program: 19751985, Technical Report No. ORNL-6303, Oak Ridge National Laboratory, Oak Ridge, Tennessee.

5. Messner, M. C. and Sham, T.-L., (2017), FY17 Status Report on the Initial EPP Finite Element Analysis of Grade 91 Steel, Technical Report No. ANL-ART-94, Argonne National Laboratory, Chicago, IL.

6. Messner, M. C., Wang, Y., Jetter, R. I. and Sham, T.-L., (2018a), “A basis for applying elastic perfectly-plastic design methods to cyclic softening materials," to appear in Proceedings of the ASME 2018 Pressure Vessels and Piping Division Conference, Prague, Czech Republic, July 2018, PVP2018-84103, American Society of Mechanical Engineers, New York, NY

7. Messner, M. C., Jetter, R. I and Sham, T.-L., (2018b), Establishing temperature upper limits for the ASME Section III, Division 5 design by elastic analysis methods. To appear in Proceedings of the ASME 2018 Pressure Vessels and Piping Division Conference, Prague, Czech Republic, July 2018, PVP2018-84105, American Society of Mechanical Engineers, New York, NY

8. Messner, M. C., (2018c), Physically-based mechanism model of creep and creep-rupture in G91, Advanced Materials R\&D Program Review, DOE Headquarters, Germantown, MD

9. Wang, Y., Sham, T.-L, and Jetter, R. I., (2013), Progress report on the development of test procedure for the two-bar thermal ratcheting experiment for Alloy 617, ORNL/TM-2013/318, Oak Ridge National Laboratory, Oak Ridge, TN.

10. Wang, Y., Jetter, R. I. and Sham, T.-L, (2014), Application of Combined Sustained and Cyclic Loading Test Results to Alloy 617 Elevated Temperature Design Criteria, ORNL/TM-2014/294, Oak Ridge National Laboratory, Oak Ridge, TN.

11. Wang, Y., Jetter, R. I., Baird, S. T., Pu, C. and Sham, T.-L., (2015), Report on FY15 Two-Bar Thermal Ratcheting Test Results, ORNL/TM-2015/284, Oak Ridge National Laboratory, Oak Ridge, TN.

12. Wang, Y., Jetter, R. I., and Sham, T.-L., (2016a), "FY16 Progress Report on Test Results In Support Of Integrated EPP and SMT Design Methods Development” ORNL/TM-2016/330, Oak Ridge National Laboratory, Oak Ridge, TN. 
13. Wang, Y., Jetter, R. I., and Sham, T.-L., (2016b), Preliminary Test Results in Support of Integrated EPP and SMT Design Methods Development, ORNL/TM-2016/76, Oak Ridge National Laboratory, Oak Ridge, TN.

14. Wang, Y., Messner and Sham, T.-L., (2017a), "FY17 Status Report on Testing Supporting the Inclusion of Grade 91 Steel as an Acceptable Material for Application of the EPP Methodology”, ORNL/TM-2017/388, Oak Ridge National Laboratory, Oak Ridge, TN.

15. Wang, Y., Jetter, R. I., Messner, M., Mohanty, S., and Sham, T.-L., (2017b), “Combined Load and Displacement Controlled Testing to Support Development of Simplified Component Design Rules for Elevated Temperature Service”, Proceedings of the ASME 2017 Pressure Vessels and Piping Conference, PVP2017-65455. 


\title{
ELECTRONIC DISTRIBUTION
}

$\begin{array}{ll}\text { Name } & \text { Affiliation } \\ \text { Lesica, S. } & \text { DOE-NE } \\ \text { Sowinski, T. E.. } & \text { DOE } \\ \text { Grandy, C. } & \text { ANL } \\ \text { Hill, R.N. } & \text { ANL } \\ \text { Jetter, R.I. } & \text { R.I. Jetter Consulting } \\ \text { Lara-Curzio, E. } & \text { ORNL } \\ \text { Li, M. } & \text { ANL } \\ \text { Lin, L. } & \text { ORNL } \\ \text { McMurtrey, M. } & \text { INL } \\ \text { Messner, M.C. } & \text { ANL } \\ \text { Sham, T.-L. } & \text { ANL } \\ \text { Zhang, Xuan } & \text { ANL } \\ \text { Wang, H. } & \text { ORNL } \\ \text { Wang, Y. } & \text { ORNL } \\ \text { Wright, R.N. } & \text { INL }\end{array}$

\author{
Email \\ sue.lesica@nuclear.energy.gov \\ thomas.sowinski@nuclear.energy.gov \\ cgrandy@anl.gov \\ bobhill@anl.gov \\ bjetter@sbcglobal.net \\ laracurzioe@ornl.gov \\ mli@anl.gov \\ linl@ornl.gov \\ michael.mcmurtrey@inl.gov \\ messner@anl.gov \\ ssham@anl.gov \\ xuanzhang@anl.gov \\ wangh@ornl.gov \\ wangy3@ornl.gov \\ richard.wright@inl.gov
}

